ICRES 2018: International Conference on Robot

Ethics and Standards, Troy, NY, 20-21 August 2018.

https://doi.org/10.13180/icres.2018.20-21.08.004

\title{
Drones and Data Protection Issues
}

\author{
Nicola Fabiano \\ Studio Legale Fabiano, Via Luigi Tosti 3, \\ Rome, 00179, Italy \\ E-mail: info@fabiano.law \\ www.fabiano.law
}

\begin{abstract}
The European Regulation 2016/679 (General Data Protection Regulation - GDPR) is a revolution because it changes the perspective on this theme radically. The GDPR provides principles to protect the rights and freedoms of natural persons. Technicians, very often, ignore any legal references paying attention almost entirely to the scientific aspects. Indeed, the GDPR applies to any sector everywhere equally. Regarding drones, apart from the civil liability as a traditional area, the GDPR has a real impact on this domain both for the respect of the law provisions and for the concrete adoption of the principles, especially during the design phase. This contribution presents some of the aspects related to drones and data protection according to the GDPR.
\end{abstract}

Keywords: Drones, Data Protection, Privacy, Security.

\section{The European legal framework on drones}

In Europe, the legislation about drones is the REGULATION (EC) No 216/2008 OF THE EUROPEAN PARLIAMENT AND OF THE COUNCIL of 20 February 2008 on common rules in the field of civil aviation and establishing a European Aviation Safety Agency, and repealing Council Directive 91/670/EEC, Regulation (EC) No 1592/2002 and Directive 2004/36/EC. ${ }^{1}$

There is a Proposal for a REGULATION OF THE EUROPEAN PARLIAMENT AND OF THE COUNCIL on common rules in the field of civil aviation and establishing a European Union Aviation Safety Agency, and repealing Regulation (EC) No 216/2008 of the European Parliament and of the Council. ${ }^{2}$

Generally speaking, it is possible to distinguish between manned and unmanned aircraft. Drones are classified as "unmanned aircraft" (UA).

Apart from the before mentioned European legislation, there are the domestic ones and the specific regulation issued by the International Civil Aviation Organization (ICAO) and Aviation National Authorities.

The before mentioned proposal for Regulation introduces a large number of significant innovation and especially about the definitions because it identifies the $\mathrm{UA}^{\mathrm{a}}$. Moreover, the proposal describes the safety information.

The EASA ${ }^{3}$ clarified that for drones it is possible to distinguish two main types of risks:

- air risks (collision with a manned aircraft or another UA); and

- ground risks (collision with persons or critical infrastructure)

Pinpointing the risks it is crucial to prevent the consequences of civil liability. In fact, drones can also imply civil liability in case of damages occurred to someone or something.

\footnotetext{
article 2:

1. "unmanned aircraft system (UAS)" means the unmanned aircraft (UA) and the equipment to control the UA remotely;

5. "unmanned aircraft (UA)" means any aircraft operating or designed to operate autonomously or to be piloted remotely without a pilot on board.
} 
It is necessary to have insurance to cover all the risks that a drone can potentially cause.

\section{The European Law on the processing of persona data}

Apart from the aforementioned European law about drones, we have to mention the EU Regulation n. 2016/679 (General Data Protection Regulation - GDPR). ${ }^{4}$

In Europe, the protection of natural persons about the processing of personal data is a fundamental right. In fact, the Article 8 of the Charter of Fundamental Rights of the European Union (the 'Charter' ${ }^{5}$ is related to the protection of natural persons about the processing of personal data ${ }^{b}$.

Furthermore, the Charter considers also the respect for private and family life $^{c}$ as a crucial aspect of privacy.

Moreover, the Treaty on the Functioning of the European Union (TFEU) ${ }^{6}$ considers the right to the protection of personal data ${ }^{\mathrm{d}}$.

In 2016 it has been published the European Regulation number 2016/679 that entered into force on 25 May 2016, but it applies from 25 May 2018. ${ }^{4}$ According to the Article 94, this Regulation will repeal the previous European legislation on data protection (Directive 95/46/EC ${ }^{7}$ ) with effects from 25 May 2018.

The GDPR obviously mentions the Charter of Fundamental Rights of the European Union in the first Whereas ${ }^{\mathrm{e}}$.

The primary goal of the EU Regulation 2016/679 is to harmonise the legislation of each Member State: the GDPR will be directly applicable in each European State, avoiding possible confusion among the domestic law. The GDPR introduces numerous changes, such as the Data Protection Impact Assessment (DPIA), the Data Protection by Design and by Default (DPbDbD), the data breach notification, the Data Protection Officer (DPO), the very high administrative fines in respect of infringements of the Regulation, and so on.

Regarding the protection of personal data, apart from the before mentioned GDPR, there is also the Directive $2002 / 58 / \mathrm{EC}^{8}$ concerning the processing of personal data and the protection of privacy in the electronic communications. In fact, according to the Article 95 of the GDPR, there is a relationship with this Directive ${ }^{\mathrm{f}}$.

The Directive 2002/58/CE has the aim to "to ensure an equivalent level of protection of fundamental rights and freedoms, and in particular the right to privacy, with respect to the processing of personal data in the electronic communication sector and to ensure the free movement of such data and of electronic communication equipment and services in the Community"g.

In this legal panorama, it is clear that technology and law are not at the same level

\footnotetext{
${ }^{\mathrm{b}}$ Article 8 - Protection of personal data. 1. Everyone has the right to the protection of personal data concerning him or her. 2. Such data must be processed fairly for specified purposes and on the basis of the consent of the person concerned or some other legitimate basis laid down by law. Everyone has the right of access to data which has been collected concerning him or her, and the right to have it rectified. 3 . Compliance with these rules shall be subject to control by an independent authority.

${ }^{\mathrm{c}}$ Article 7 - Respect for private and family life. Everyone has the right to respect for his or her private and family life, home and communications.

dArticle 16(1) says: "Everyone has the right to the protection of personal data concerning them".

eThe protection of natural persons in relation to the processing of personal data is a fundamental right. Article 8(1) of the Charter of Fundamental Rights of the European Union (the 'Charter') and Article 16(1) of the Treaty on the Functioning of the European Union (TFEU) provide that everyone has the right to the protection of personal data concerning him or her.

f The Article 95 says: "This Regulation shall not impose additional obligations on natural or legal persons in relation to processing in connection with the provision of publicly available electronic communications services in public communication networks in the Union in relation to matters for which they are subject to specific obligations with the same objective set out in Directive 2002/58/EC".
}

gArticle 1 
because the first one (technology) is always ahead than the second one (law). The actions on the part of the legislator always followed the technological solutions, and so the law rules have to be able to consider the technology evolution.

It is crucial to analyse the GDPR to be ready and comply with the new data protection Regulation. In fact, the General Data Protection Regulation (GDPR) represents an innovative data protection law framework, because of several purposes on which is based and strictly related to the technical solutions.

\subsection{Data Protection and Privacy}

Very often people talk about data protection, but using the term "privacy" as a synonym, confusing the real meaning indeed. "Privacy" and "Data Protection" are not the same because, apart from the definition, they are different concepts. Both are fundamental rights in Europe, but there are differences between them.

On the one hand privacy is related to the personal life; on the other hand, data protection concerns the protection of natural personal about the processing of personal data.

It is not possible to address data protection and privacy issues adopting only technical solutions without any legal reference. Apart from the highly technical measure, hence, we cannot dismiss the law obligations, where they are applicable, like in Europe, according to the GDPR. ${ }^{4}$ In fact, an approach considering the legal framework, confirms the equation according to security is not equal to privacy. A system could be very secure but not compliance with the data protection law. On the contrary, a system could be compliance with the data protection law and, hence, very secure (obviously only by the adoption of security measures).

\section{Drones and Data Protection}

One of the main legal issues is related to the personal data protection law (GDPR). First of all, it is essential to highlight the territorial scope according to the article 3 of the GDPR, because the EU Regulation 2016/679 applies in all over the world regardless of whether the processing takes place in the Union or not. In fact, just according to the article as mentioned earlier, 3, paragraph 1, "This Regulation applies to the processing of personal data in the context of the activities of an establishment of a controller or a processor in the Union, regardless of whether the processing takes place in the Union or not". Moreover, the paragraph 2 of the same article 3, states "This Regulation applies to the processing of personal data of data subjects who are in the Union by a controller or processor not established in the Union, where the processing activities are related to:

(a) the offering of goods or services, irrespective of whether a payment of the data subject is required, to such data subjects in the Union; or

(b) the monitoring of their behaviour as far as their behaviour takes place within the Union".

Regarding this topic, the European Data Protection Board (EDPB) carried out the "Guidelines 3/2018 on the territorial scope of the GDPR - Adopted on 16 November 2018". 9

Apart from the territorial scope, we must distinguish the use of drones from designing of them. In case of use of drones, the user has to pay attention to the data protection and privacy laws, according to which people have to respect data subject's rights and personal life.

Regarding the use of drones, for example, very often people install cameras to acquire photo or video, but according to the law, it is allowed to acquire images or video only in a public place. In fact, it is not permitted to obtain pictures of a natural person in a private 
area without his/her consent, and this can be the case of unlawful processing of personal data.

Regarding the design of drones, we have to apply other rules laid down in the GDPR and especially the principle "data protection by design" according to the article 25 of the GDPR, where any infringement of this provision shall be subject to administrative fines up to 10.000 .000 EUR, or in the case of an undertaking, up to $2 \%$ of the total worldwide annual turnover of the preceding financial year ${ }^{\mathrm{h}}$. The principle laid down in the Article 25 , paragraph 1, of the GDPR is the data protection by design, and it means that during the design phase the controller " shall, both at the time of the determination of the means for processing and at the time of the processing itself, implement appropriate technical and organisational measures, such as pseudonymisation, which are designed to implement dataprotection principles, such as data minimisation, in an effective manner and to integrate the necessary safeguards into the processing in order to meet the requirements of this Regulation and protect the rights of data subjects". This principle means that the controller is responsible for, and can demonstrate compliance with, the principles contained in the Article 5, paragraph 1, of the GDPR.

Moreover, the user of drones (controller or processor) has to respect the security measures according to the GDPR, by implementing "appropriate technical and organisational measures to ensure a level of security appropriate to the risk"

One of the main risks is the unlawful collection of personal data. ${ }^{10}$

Ethics entails a consciousness about the high values belonging to a natural person. People have to respect human dignity and Ethics both using or designing a drone. It is not simple to define Ethics, but we believe that it is essential to raise awareness. The risk is that natural person becomes pure data, debasing and losing so the typical aspects belonging to a human. Ethics is the correct path to preserve the ontological nature of human.

What is ethics?

There are no easy answers because we have several definitions. We want to refer to a thinking way helpful to distinguish, generally speaking, what is wrong from what is right, finding the right key to conferring a natural person the exact value belonging to him or her.

The GDPR doesn't lay down any specific rules on Ethics. Nevertheless, we think that it is possible to start applying the GDPR principles thinking ethical: it is a matter of approach even without any norm.

Apart from the laws, in the processing of personal data, each controller should consider ethics anyway also even does not exist any obligation provided by the law.

A consciousness of ethics entails the comply with the law (data protection law - GDPR), but it could not true the contrary (respecting the law does not mean to have always consciousness of ethics).

\section{Conclusion}

Drones can imply risks for natural persons regarding the protection of personal data.

The protection of personal data is entirely relevant not only regarding the use of drones and the consequences of civil liability but also during the design phase. In fact, designing drones technicians have to pay attention to the data protection by design and by default

\footnotetext{
${ }^{\mathrm{h}}$ Article 83, paragraph 4 letter (a) of the GDPR

${ }^{i}$ The Article 4, paragraph 1, of the GDPR defines the controller as "the natural or legal person, public authority, agency or other body which, alone or jointly with others, determines the purposes and means of the processing of personal data; where the purposes and means of such processing are determined by Union or Member State law, the controller or the specific criteria for its nomination may be provided for by Union or Member State law"

jArticle 32 of the GDPR
} 
principles according to the GDPR. However, to develop drones, it could be used Artificial Intelligence and Machine Learning. Nowadays it is possible to design drones as a robot, and in this way, it is crucial to consider the relationship between ethics and robots fully.

Ethics and robots cannot dismiss from the data protection law and the protection of the risk of varying likelihood and severity for the rights and freedoms of natural persons.

\section{References}

1. REGULATION (EC) No 216/2008 OF THE EUROPEAN PARLIAMENT AND OF THE COUNCIL of 20 february 2008 on common rules in the field of civil aviation and establishing a european aviation safety agency, and repealing council directive 91/670/eec, regulation (ec) no 1592/2002 and directive 2004/36/ec (2008), http://eur-lex.europa.eu/legal-content/ $\mathrm{EN} / \mathrm{TXT} / \mathrm{PDF} /$ ?uri=CELEX : 02008R0216-20130129\&f rom=EN.

2. Proposal for a REGULATION OF THE EUROPEAN PARLIAMENT AND OF THE COUNCIL on common rules in the field of civil aviation and establishing a european union aviation safety agency, and repealing regulation (ec) no 216/2008 of the european parliament and of the council (2015), http://eur-lex.europa.eu/resource.html?uri=cellar: da8dfec1-9ce9-11e5-8781-01aa75ed71a1.0001.02/DOC_1\&format=PDF.

3. E. A. S. Agency, Opinion no 01/2018 - introduction of a regulatory framework for the operation of unmanned aircraft systems in the 'open' and 'specific' categories (2018), https://www. easa. europa.eu/sites/default/files/dfu/Opinion\%20No\%2001-2018.pdf.

4. REGULATION (EU) 2016/679 OF THE EUROPEAN PARLIAMENT AND OF THE COUNCIL of 27 april 2016 on the protection of natural persons with regard to the processing of personal data and on the free movement of such data, and repealing directive 95/46/ec (general data protection regulation) (2016), https://eur-lex.europa.eu/legal-content/EN/ TXT/PDF/?uri=CELEX : 32016R0679\&from=EN.

5. Charter of fundamental rights of the european union (2012), http://eur-lex.europa.eu/ legal-content/EN/TXT/PDF/?uri=CELEX : 12012P/TXT\&from=EN.

6. The treaty on the functioning of the european union (2012), https://eur-lex.europa.eu/ legal-content/EN/TXT/PDF/?uri=CELEX : 12012E/TXT\&from=EN .

7. DIRECTIVE 95/46/EC OF THE EUROPEAN PARLIAMENT AND OF THE COUNCIL of 24 october 1995 on the protection of individuals with regard to the processing of personal data and on the free movement of such data (1995), http://eur-lex.europa.eu/legal-content/ EN/TXT/PDF/?uri=CELEX : 31995L0046\&from=EN.

8. DIRECTIVE 2002/58/EC OF THE EUROPEAN PARLIAMENT AND OF THE COUNCIL of 12 july 2002 concerning the processing of personal data and the protection of privacy in the electronic communications (2002), http://eur-lex.europa.eu/legal-content/EN/TXT/PDF/ ?uri $=$ CELEX : 32002 L0058\& $\mathrm{from}=\mathrm{en}$.

9. Guidelines $3 / 2018$ on the territorial scope of the gdpr (2018), https://edpb.europa.eu/sites/ edpb/files/files/file1/edpb_guidelines_3_2018_territorial_scope_en.pdf.

10. Office of the Information Commissioner Queensland, GUIDELINE Drones and the Privacy Principles (2018),

https: //www.oic.qld.gov.au/guidelines/for-government/guidelines-privacy-principles/ applying-the-privacy-principles/drones-and-the-privacy-principles. 